\title{
On the merits and pitfalls of introducing a digital platform to aid conservation management: volunteer data submission and the mediating role of volunteer coordinators
}

Article

Accepted Version

Creative Commons: Attribution-Noncommercial-No Derivative Works 4.0

Arts, K., Melero, Y., Webster, G., Sharma, N., Tintarev, N., Tait, E., Mellish, C., Sripada, S., MacMaster, A.-M., Sutherland, H., Horrill, C., Lambin, X. and van der Wal, R. (2020) On the merits and pitfalls of introducing a digital platform to aid conservation management: volunteer data submission and the mediating role of volunteer coordinators. Journal of Environmental Management, 265. 110497. ISSN 0301-4797 doi: https://doi.org/10.1016/j.jenvman.2020.110497 Available at https://centaur.reading.ac.uk/90641/

It is advisable to refer to the publisher's version if you intend to cite from the work. See Guidance on citing.

Published version at: http://dx.doi.org/10.1016/j.jenvman.2020.110497

To link to this article DOI: http://dx.doi.org/10.1016/j.jenvman.2020.110497

Publisher: Elsevier

All outputs in CentAUR are protected by Intellectual Property Rights law, 
including copyright law. Copyright and IPR is retained by the creators or other copyright holders. Terms and conditions for use of this material are defined in the End User Agreement.

\section{www.reading.ac.uk/centaur}

\section{CentAUR}

Central Archive at the University of Reading

Reading's research outputs online 

conservation management: volunteer data submission and the mediating role of volunteer coordinators

Koen Arts a,b,1,*, Yolanda Melero c,d,1, Gemma Webster e, Nirwan Sharma b, Nava

6 Tintarev f, Elizabeth Tait g, Christopher Mellish h, Somayajulu Sripada h, Ann-Marie MacMaster i, Hollie Sutherland j, Chris Horrill i, Xavier Lambin k, Rene van der Walı,m

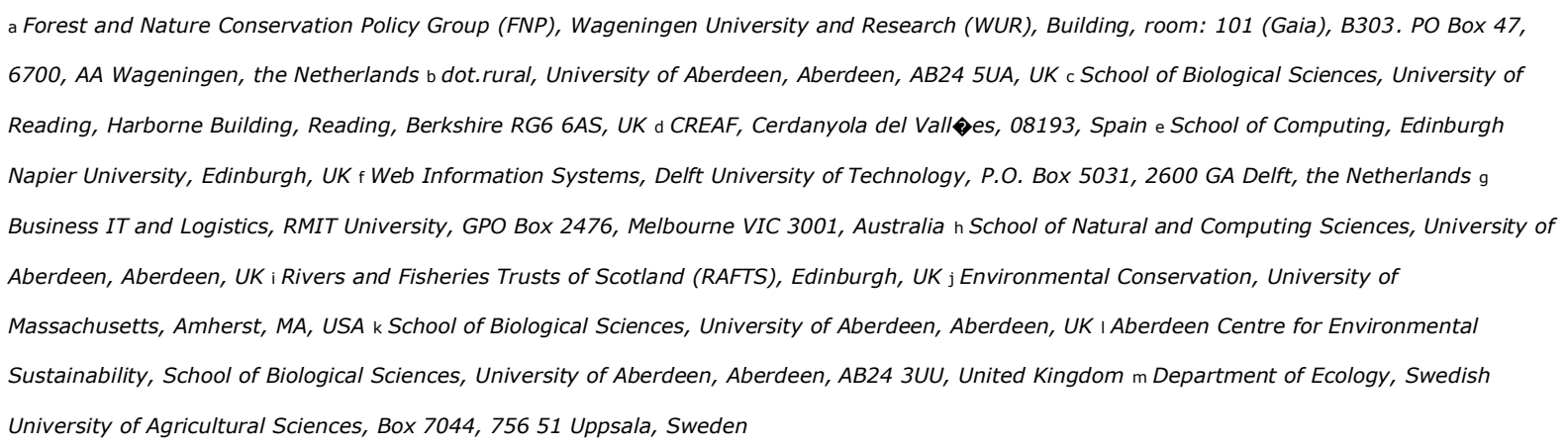

\section{Abstract}

Against a backdrop of accelerating digital innovation in nature conservation and environmental management, a real-world experiment was conducted with the research aims of assessing: 1) the effects of introducing a digital data-entry platform on volunteer data submission; and 2) the extent to which coordinators influence digital platform use by their volunteers. We focussed on a large-scale volunteer-based initiative which aims to eradicate the non-native American mink (Neovison vison) from northern Scotland. This geographically dispersed conservation initiative adopted a digital platform which allowed volunteers to submit records to a central database. We found that the platform had a direct and positive effect on volunteer data submission behaviour, increasing both the number and frequency of submissions. However, our analysis revealed striking differences in coordinator engagement with the platform, which in turn influenced the engagement of volunteers with this centrally introduced digital innovation. As a consequence, the intended organisation-wide rolling out of a digital platform translated into a diversely-implemented innovation, limiting the efficacy of the tool and revealing key challenges for digital innovation in geographically-dispersed conservation initiatives. 
Highlights:

- Digital innovation is often enthusiastically employed but effects poorly studied

- We build a data-entry platform to assist a geographically-dispersed organisation

- The centralised platform increased data submission by volunteers

- Digital tools need be introduced with caution and attention for mediating effects

Key words: Volunteer-based management; Technological innovation; Environmental citizen science; Human-computer interaction; Invasive species control; Volunteer coordination. 


\section{Introduction}

\subsection{Data submission through a digital platform}

Environmental management increasingly makes use of digital technologies (Arts et al., 2015;

Bakker and Ritts, 2018; Sullivan et al., 2014). The prominent use of the internet in environmental citizen science is a clear example (Dickinson et al., 2010; Kelling et al., 2015; Kobori et al., 2016). Digital technologies provide new and often user-friendly ways of generating, handling, organising, analysing, and communicating data and information (Chapron, 2015; Stein, 2008). The promise of more data and opportunity to scale up operations has led many conservation organisations to adopt advanced digital hardware and software such as drones and apps (Galán-Díaz et al., 2015; Miller-Rushing et al., 2012). While the practical benefits may be taken for granted, they are not guaranteed (Druschke and Seltzer, 2012; Gallo and Waitt, 2011; Jordan et al., 2012). For example, the interpretation of citizen science data is often clouded by concerns regarding their accuracy, quality and reliability (Kremen et al., 2011; Wiersma, 2010). Also, without online tools that engage and are well aligned with project goals, projects may fail to acquire sufficiently large datasets over prolonged periods of time (Van der Wal et al., 2016; Wald et al., 2016). New tools may change the nature of a volunteers' engagement with conservation, and this may in turn be influenced by how coordinators of conservation volunteers (hereafter conservation coordinators) decide to introduce such tools to their volunteers. This paper engages that topic. Social processes are known to strongly influence volunteering (Asah and Blahna, 2012; Bruyere and Rappe, 2007; Pagès et al., 2018). Yet, in spite of the 'missiondriven' character of nature conservation (Mace, 2014), many digital innovations in this realm are introduced without their social impacts being studied (Arts et al., 2015). Here we 
focus on a common innovation in nature conservation, namely the introduction of a new data reporting platform, and set out to address two research aims: 1) to assess whether volunteer data submission (i.e. number and frequency of submission, and number of records in a single submission, a.k.a. batch size) changes with the use of a digital platform; and 2) to determine to what extent coordinators influence the usage of a digital platform by their volunteers. The first aim was addressed by means of a randomised experimental setup linked to a real-world nature conservation case (Section 3.1). The second aim was investigated through mixed qualitative methods (Section 3.2).

\subsection{Context of study}

This study revolved around the Scottish Mink Initiative (SMI), one of the world's largest volunteer-based invasive species management programmes in terms of area covered (approximately $29,500 \mathrm{~km}^{2}$ ). The objective of the initiative was the detection and subsequent removal of the invasive American mink (Neovison vison, mink hereafter) across northern Scotland (Bryce et al., 2011; Melero et al., 2015). Volunteers were recruited by SMI to adopt and operate one or more rafts used for monitoring. The rafts are required to be checked every 10-14 days. If mink is detected, volunteers can request and operate a trap. At the time of study, volunteers were directed by four full-time employed coordinators, each operating in regions of different size and geography (Figure 1). 

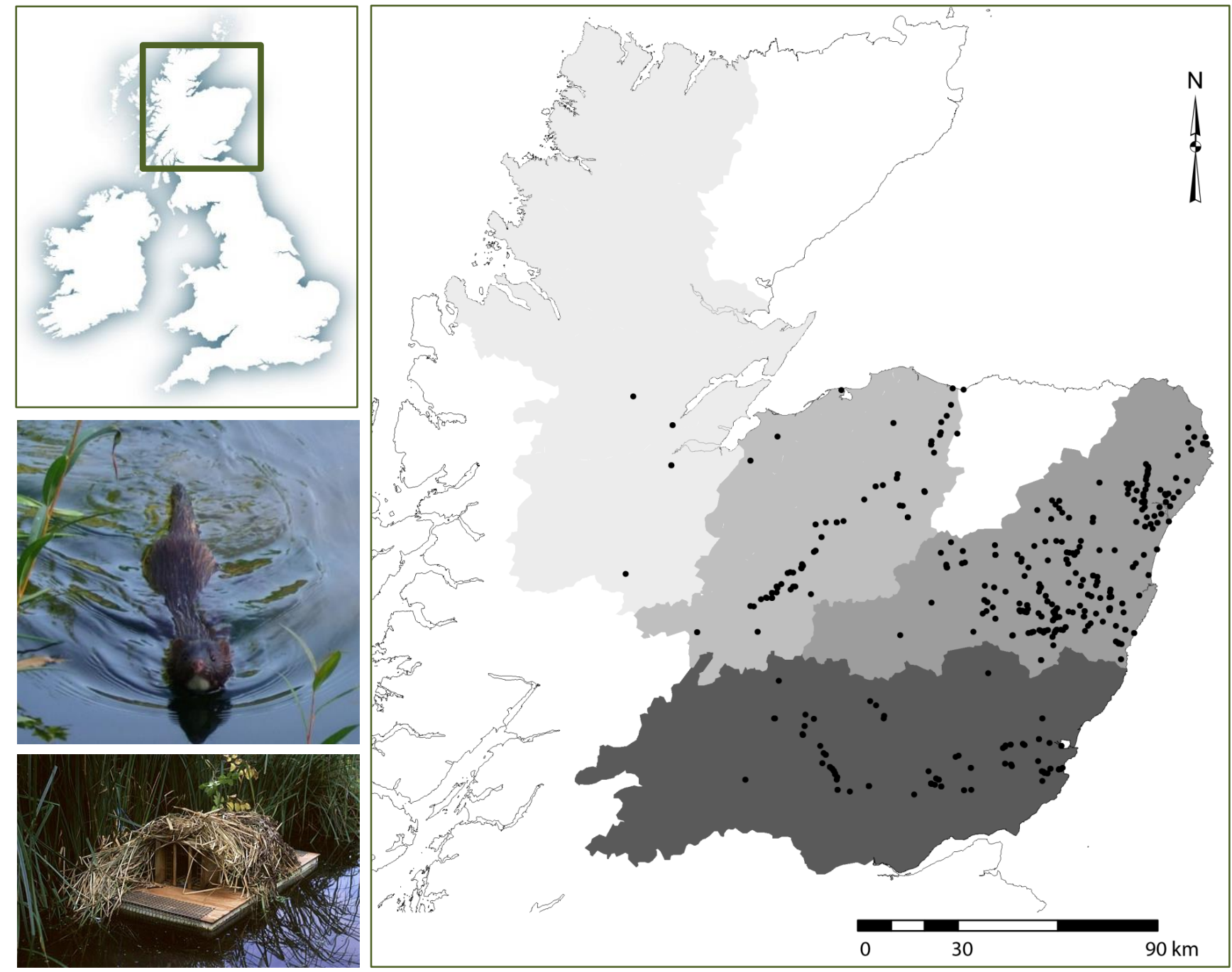

Figure 1. Images of an American mink and raft, and maps of northern Scotland with mink captures (black dots) from April 2011 to January 2013 in the four experimental focal regions of the coordinators $(C)$, from lightest grey to darkest grey respectively: C-Highlands, C-Cairngorms, C-Aberdeenshire, and C-Tayside.

Volunteers were asked to report all mink signs recorded on their raft to their regional

coordinator. Typical means for doing so included phoning, texting, emailing, and face-to-

face interaction. Raft check records were either 'absence records' (no signs of mink) or

'positive records' (footprints or scats). A digital data-entry submission platform was

developed with SMI that allowed volunteers to report to a central database through a web 


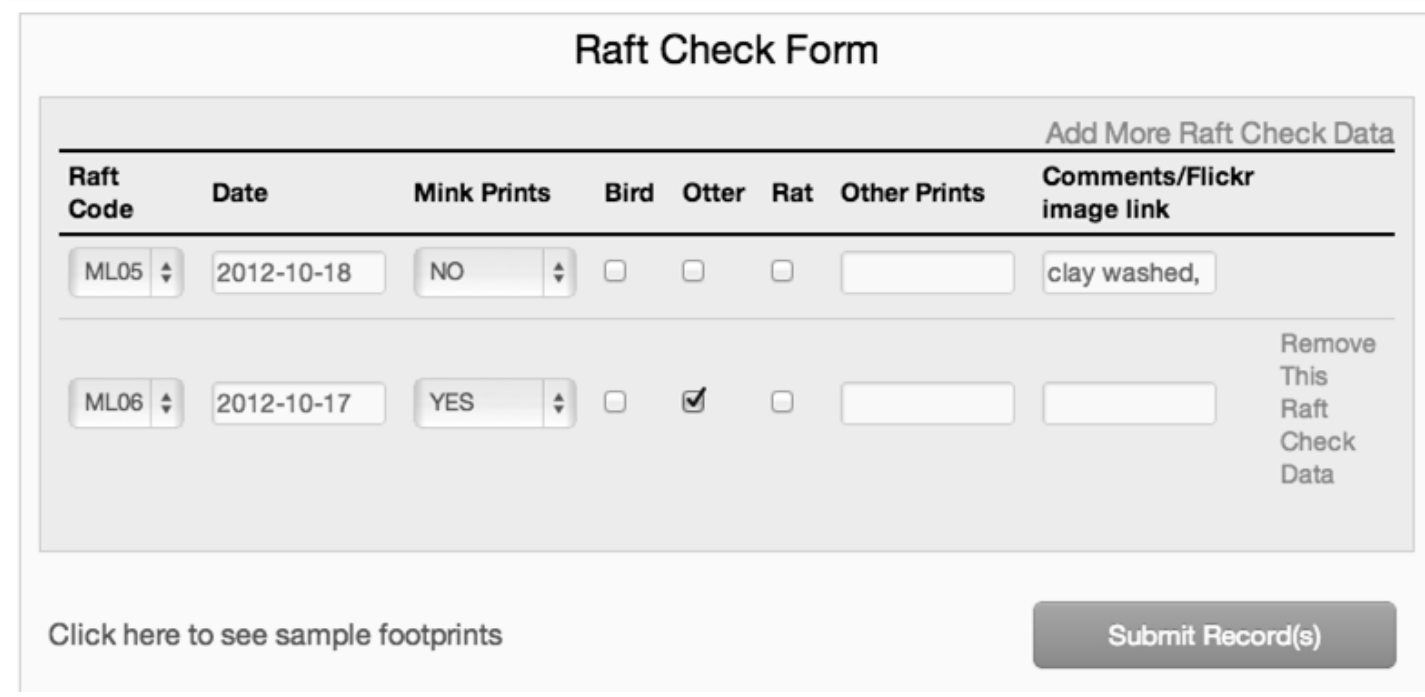

Figure 2. Screenshot of the 'raft check form' as part of the digital submission platform.

The primary goal for SMI was to improve efficiency of data collection and data processing in this geographically dispersed initiative. The platform was tested and improved upon for over a year. The experiment with the platform ran for 9.5 months; thereafter, SMI continued on a smaller funding base with a changed organisational structure, providing a natural end to us studying the digital innovation.

\section{Materials and methods}

\subsection{Experimental approach}

At the start of the experiment all volunteers conducting raft checks were randomly divided into a control group (one-third) and treatment group (two-thirds). Control volunteers were not informed about the online platform. Treatment volunteers were invited (up to $3 x$ ) to use the platform (i.e. submit raft checks online), receiving full instruction via email or hard copy letters depending on their preferred mode of communication. Coordinators were asked to take into account treatment allocation when dealing with their volunteers. Three control group volunteers became aware of the platform and requested permission to use it. 
Some shifting was expected and permission was granted. During the experimental period, 60 different volunteers (15 control, 45 treatment) contributed 776 raft check submissions. The experimental set-up resulted in four distinct groups:

A. Control group but using platform ( $n=3$ volunteers, with in total 62 submissions);

B. Treatment group and using platform ( $n=25,540$ submissions);

C. Control group and not using platform ( $n=12,67$ submissions);

D. Treatment group but not using platform ( $n=20,107$ submissions).

Differences in submission behaviour were tested for by contrasting control $(A+C)$ and treatment $(B+D)$ groups and two specific further comparisons ( $B$ vs. $C$ and $B$ vs. $D$ ) using three indicators: 1) number of raft checks submitted per volunteer; 2) frequency of submission, i.e. the number of times each volunteer logged in to submit their data, with a higher frequency pointing at a more convenient and direct way for volunteers to submit data; and 3) mean batch size, i.e. the number of raft checks submitted per volunteer divided by their frequency of submission, with low mean batch size indicating less delay between raft checks and submission of records. Differences in the number and frequency of submissions were tested for using GLMs with negative binomial error distribution and loglink function to model the over-dispersed count data appropriately. Differences in mean batch size were also tested for with GLMs but using a gamma distribution with log-link as the coefficients of variation were positive, continuous, skewed to the left and increasing with the mean (Bates et al. 2015). All GLMs were run using the Ime4 package of R 3.2.2. For each indicator a global model containing the factors treatment, coordinator, and coordinator $\times$ treatment was fitted and followed up with model simplification and selection using AIC ( $\triangle \mathrm{AIC}<2$; see Results section). 


\subsection{Qualitative social analysis}

To investigate how coordinators engaged with the new digital platform, we determined how they approached their role in relation to SMI and the platform, using the concepts of respectively 'organisational orientation' and 'innovation orientation' (cf. Pruden, 1973; Tibbles et al., 2008). Three sources of data were used:

- Semi-structured, face-to-face interviews conducted during the platform's development phase with the coordinators and others closely involved, such as SMI's director ( $\mathrm{n}=9$, mean duration: 39 minutes). These interviews were aimed at understanding the methods and social structures of the organisation, SMI's relationship with its volunteers, and the perceived potential role of digital technology. For reflections on the impact of the platform and volunteer-related matters, follow-up interviews were conducted with SMI's director and coordinators at the end of the experiment period $(n=5$, mean duration: 37 minutes). All 14 interviews were recorded and transcribed verbatim.

- Email communications with coordinators concerning questions posed after the end of the experiment relating to: best volunteers, impacts of platform on e.g. volunteer retention and volunteer performance.

- Coordinators' diaries to capture all daily interaction with their volunteers for two months. Diary entries comprised duration, medium and initiator of contact, as well as the reason for contact. This resulted in 13 handwritten A5 pages by coordinator CAberdeenshire, 45 by C-Cairngorms, 4 by C-Highlands and 31 by C-Tayside.

Analysis of these sources of data consisted of qualitative classifications of the text; common themes in the data were abstracted by means of deductive coding using NVivo software (cf. discourse analysis - Hajer et al., 2006; Jørgensen and Phillips, 2002; Thomas, 2006). Subsequently, as an inductive part of the analysis (Fereday and Muir-Cochrane, 2006), these 
themes were used to assess the coordinators' organisational and innovation orientation using the following two typologies:

- Organisational orientation (typologies of employees - McCroskey et al., 2005; Pruden, 1973): upward mobiles (react positively to key managerial decisions [such as the introduction of a digital platform] and can thrive in the new situation); indifferents (by and large uncommitted to a key managerial decision); ambivalents (show signs of both positivity and lack of commitment).

- Innovation orientation (perspectives on Information and Communications Technology (ICT) - Arts et al., 2016; Bekkers et al., 2006; Siguaw et al., 2006): technological perspective (ICT approached as a set of tools to achieve specific goals); organisational perspective (emphasising capacities of ICT to process information, organise work and improve communication); conceptual perspective (ICT used as a lens to understand practices).

\section{Results}

\subsection{Experimental approach}

Best models for all three indicators tested for (number of submissions, frequency of submission and mean batch size) included 'treatment' and 'coordinator' but not their interactions (all $\triangle \mathrm{AIC}>4$ ). Treatment volunteers (group B+D) provided 1.6× more submissions, and did so $1.8 \times$ more frequently than control volunteers (group $A+C$ ), though neither odds-ratio was significant (Figure 3). Most prolific were control group volunteers who nevertheless used the platform (group $A, n=3$ ), but their low number precluded statistical testing. Treatment volunteers using the platform (group B) generated 3.9× more 
submissions than control volunteers not using the platform (group C) and $4.0 \times$ more than treatment volunteers not using the platform (group D). With regard to frequency of submission, treatment volunteers using the platform (group B) scored again higher, with $4.4 \times$ (vs. group C) and $4.5 \times$ higher values (vs. group D). As a result, the mean batch size was $1.7 \times$ lower in the treatment group compared to the control group. A similar (1.6x) and likewise significant difference was found when comparing batch sizes of treatment volunteers using the online system (group B) with control volunteers not using the system (group C). However, comparison of treatment volunteers using (group B) versus not using (group D) the system revealed similarly low batch sizes. 


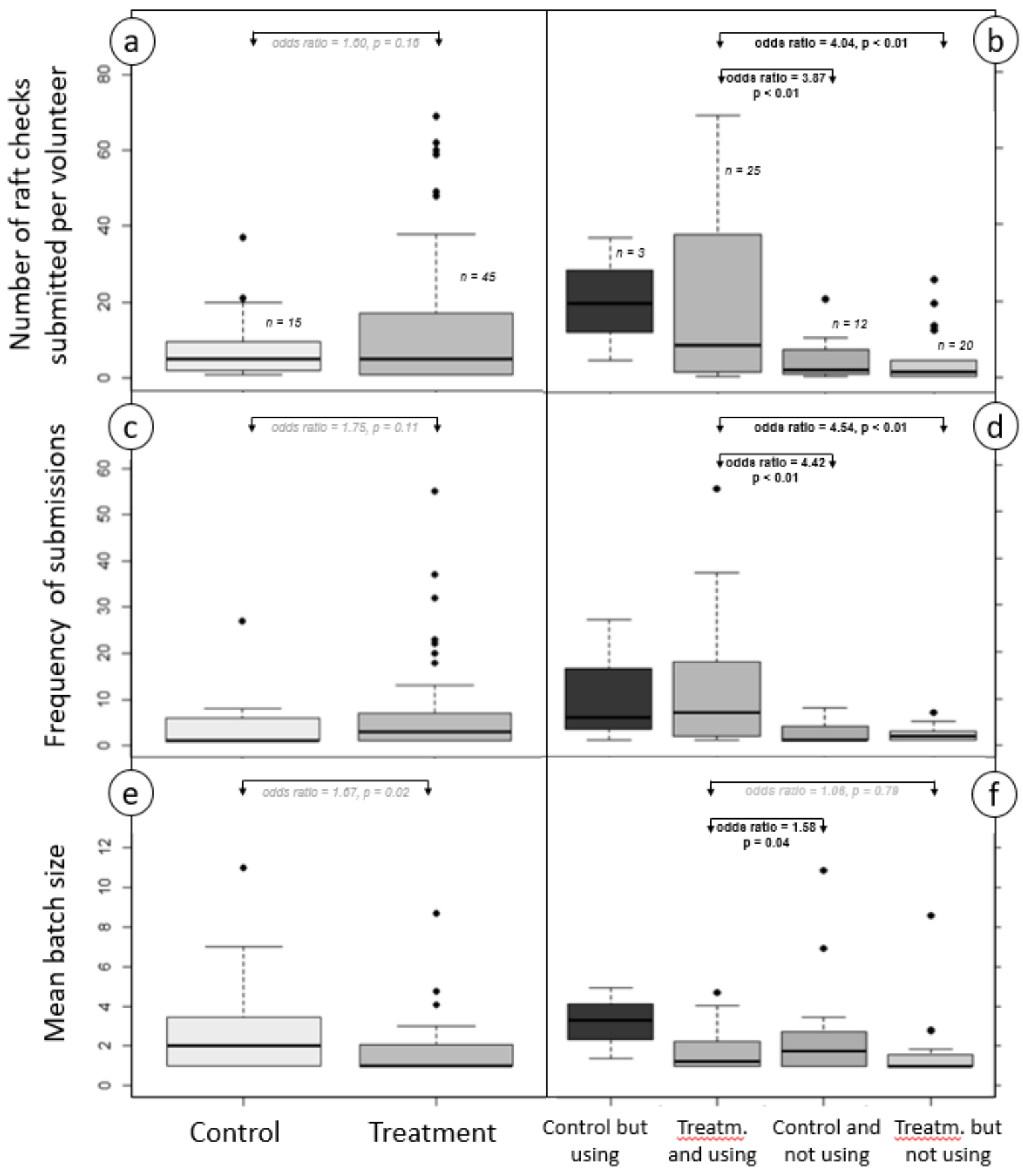

Figure 3. Boxplots of number of raft checks submitted per volunteer $(a, b)$, frequency of submissions $(c, d)$ and mean batch size $(e, f)$. Panels $a, c$ and $d$ provide summary statistics for the two intended treatment groups (control vs. treatment) and panels $b$, $d$ and ffor the four realised treatment groups. Depicted are the median, 1st and 3rd quantiles, 95\% confidence intervals (whiskers) and outlying points. Summary test results are given for the respective contrasts; those in black indicate statistically significant differences between groups. 
211 Striking differences emerged when inspecting volunteer submissions across the four

212 coordinators (Figure 4). C-Aberdeenshire had very few associated volunteers ( $n=4)$, all of

213 which were of the treatment group (100\%) and indeed using the web portal as such (group

214 B). C-Cairngorms had considerably more associated volunteers $(n=11)$, and those were

215 primarily also from the treatment group B (90\%) and none from group C, the 'offline' control

216 group. The other two coordinators (C-Highlands and C-Tayside) had both more volunteers

217 ( $n=15$ and $n=30)$ and fewer of them were from the treatment group (44\% and $36 \%)$. This

218 included several volunteers who submitted a low number of records once or twice, which

219 significantly reduced the average number of submissions per volunteer (model deviance

$220 E s t=62.4, D f=3,53, p<0.01)$ and frequency of submission $(E s t=61.7, D f=3,55, p<0.02)$

221 compared to the other two coordinators. In fact, the coordinator with the largest number of

222 volunteers had also the greatest number of volunteers from the control group, submitting

223 occasionally and via the coordinator. 


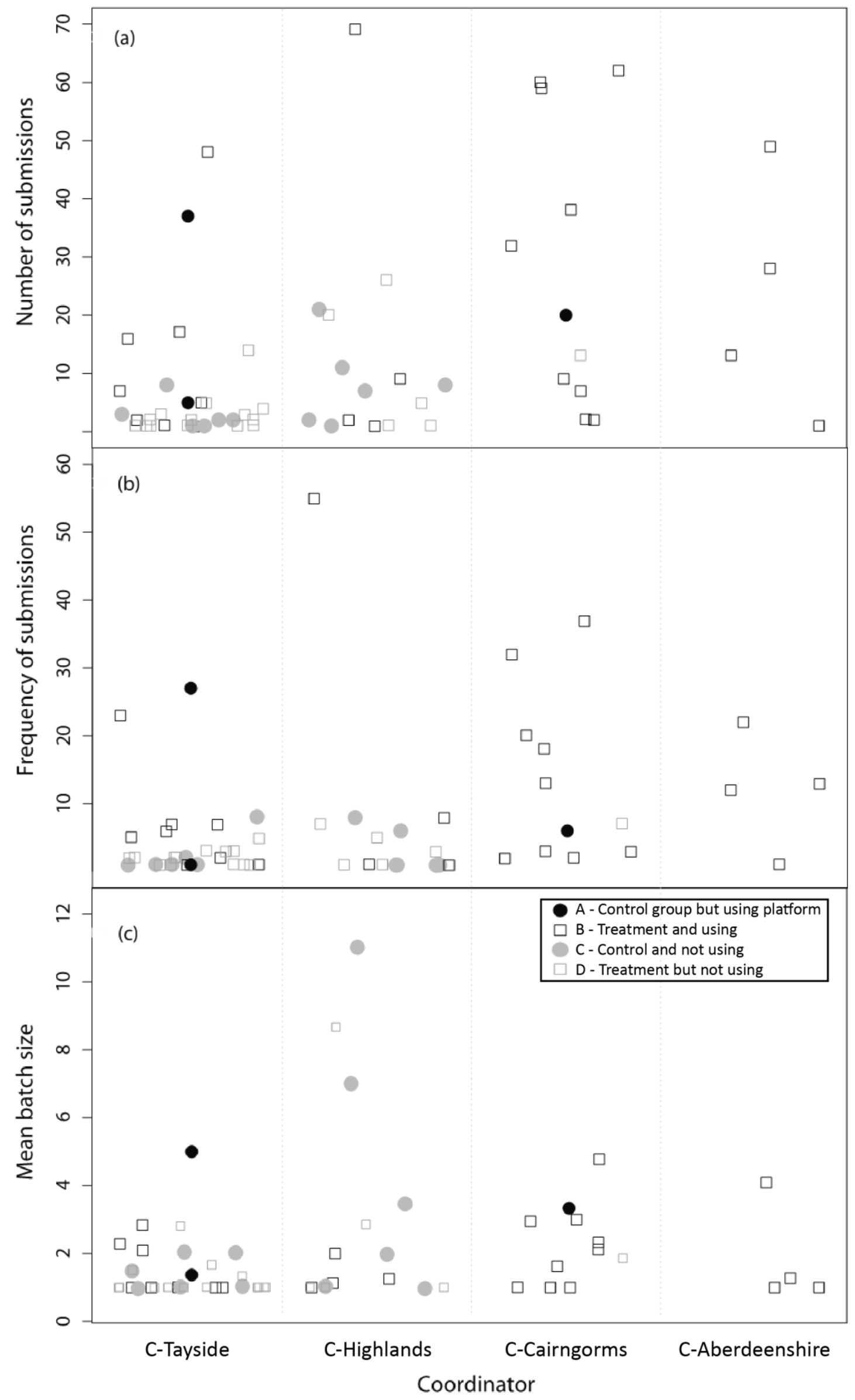


Figure 4. (a) Number of volunteer submissions, (b) frequency of submissions and (c) mean batch size, by coordinator (C-Tayside, $n=30$; C-Highlands, $n=15$; C-Cairngorms $n=11$; and $C$-Aberdeenshire, $n=4)$, and in relation to the experimental treatment categories $(A=$ Control group but using platform, $n=3 ; B=$ Treatment group and using platform, $n=25 ; C=$ Control group and not using platform, $n=12$; and $D=$ Treatment group but not using platform, $n=20$ ). Values on the $x$-axis are slightly offset to aid visualisation.

\subsection{Qualitative social analysis}

The intentions of SMI's director were to roll out the digital platform uniformly across

northern Scotland. The director observed that "it is extremely difficult for us to be able to get data and be able to manage such large areas, especially in a strategic way". Moreover, he believed that the platform would be key to the continuity and stability of the organisation: "All the future work that we are doing (...) is going to be through the [platform]." Our qualitative analysis showed, however, that there were strong differences among coordinators in their engagement with the platform. This was underpinned by the different coordinators' organisational and innovation orientations. Five dimensions of 'organisational orientation' emerged from the qualitative data, and for each dimension, coordinators demonstrated diverging views (Table 1 ).

Table 1. Classification of coordinators in relation to organisational and innovation orientations.

\begin{tabular}{|l|l|l|l|l|}
\cline { 2 - 5 } & \multicolumn{1}{c|}{ C-Tayside } & C-Highlands & C-Cairngorms & C-Aberdeenshire \\
\cline { 2 - 5 } & \multicolumn{1}{c|}{$\begin{array}{l}\text { Opwanisational } \\
\text { orientation }\end{array}$} & Ambivalent: & Upward mobile: & Ambivalent: \\
\hline $\begin{array}{l}\text { Own role within } \\
\text { organisation }\end{array}$ & $\begin{array}{l}\text { Compliance with } \\
\text { organisational } \\
\text { agreements and }\end{array}$ & Catching mink & $\begin{array}{l}\text { Establishing } \\
\text { volunteer }\end{array}$ & $\begin{array}{l}\text { Catching mink } \\
\text { and using } \\
\text { volunteers where }\end{array}$ \\
\hline
\end{tabular}




\begin{tabular}{|c|c|c|c|c|}
\hline & rules & & networks & to do this \\
\hline $\begin{array}{l}\text { - Importance of } \\
\text { data }\end{array}$ & $\begin{array}{l}\text { Promoting } \\
\text { collection of } \\
\text { records }\end{array}$ & $\begin{array}{l}\text { Little emphasis } \\
\text { on data } \\
\text { collection }\end{array}$ & $\begin{array}{l}\text { Promoting } \\
\text { collection of } \\
\text { records }\end{array}$ & $\begin{array}{l}\text { Little emphasis } \\
\text { on data } \\
\text { collection }\end{array}$ \\
\hline - Ideal volunteer & $\begin{array}{l}\text { Complies with } \\
\text { organisation }\end{array}$ & $\begin{array}{l}\text { Catches lots of } \\
\text { mink }\end{array}$ & Keeps in touch & $\begin{array}{l}\text { Catches lots of } \\
\text { mink }\end{array}$ \\
\hline $\begin{array}{ll}- & \text { Interaction with } \\
\text { volunteer }\end{array}$ & $\begin{array}{l}\text { Making it easy } \\
\text { for them }\end{array}$ & $\begin{array}{l}\text { No news is no } \\
\text { mink }\end{array}$ & $\begin{array}{l}\text { Putting } \\
\text { communication } \\
\text { onus with } \\
\text { volunteers }\end{array}$ & $\begin{array}{l}\text { No news is no } \\
\text { mink }\end{array}$ \\
\hline $\begin{array}{l}\text { Volunteer } \\
\text { feedback about } \\
\text { the platform }\end{array}$ & $\begin{array}{l}\text { Both positive and } \\
\text { negative } \\
\text { responses }\end{array}$ & $\begin{array}{l}\text { Possibly little } \\
\text { used }\end{array}$ & $\begin{array}{l}\text { Both positive and } \\
\text { negative } \\
\text { responses }\end{array}$ & $\begin{array}{l}\text { Not keen on new } \\
\text { technology }\end{array}$ \\
\hline $\begin{array}{l}\text { Innovation } \\
\text { orientation }\end{array}$ & $\begin{array}{l}\text { Technological } \\
\text { perspective: }\end{array}$ & $\begin{array}{l}\text { Organisational } \\
\text { perspective: }\end{array}$ & $\begin{array}{l}\text { Organisational } \\
\text { perspective: }\end{array}$ & $\begin{array}{l}\text { Technological } \\
\text { perspective: }\end{array}$ \\
\hline $\begin{array}{l}\text { Own interaction } \\
\text { with platform }\end{array}$ & Proficient & Proficient & Proficient & $\begin{array}{l}\text { Struggled to } \\
\text { operate }\end{array}$ \\
\hline $\begin{array}{l}\text { Expectations } \\
\text { and opinion of } \\
\text { platform }\end{array}$ & $\begin{array}{l}\text { Still double- } \\
\text { checking data } \\
\text { but better than } \\
\text { before }\end{array}$ & $\begin{array}{l}\text { Reduced } \\
\text { workload, } \\
\text { stressed } \\
\text { platform } \\
\text { importance }\end{array}$ & $\begin{array}{l}\text { Reduced } \\
\text { workload, } \\
\text { improvements } \\
\text { needed but } \\
\text { helped } \\
\text { structuring SMI }\end{array}$ & $\begin{array}{l}\text { Reduced } \\
\text { workload, } \\
\text { important for } \\
\text { uniform } \\
\text { approach to data } \\
\text { collection }\end{array}$ \\
\hline
\end{tabular}

First, regarding their own role within organisation, C-Tayside put emphasis on compliance

with the organisational agreements and rules conveyed by the director. C-Highlands was

primarily focussed on catching mink himself. The same applied to C-Aberdeenshire who

approached volunteers largely to help decide where to concentrate his efforts. C-

Cairngorms stressed the importance of establishing self-operating volunteer networks to minimise future coordinator input.

Second, on the importance of data, C-Highlands and C-Aberdeenshire put relatively little 
mink. C-Tayside and C-Cairngorms, on the other hand, kept promoting the submission of 'absence records' - deemed important to demonstrate mink absence and 'active volunteer' presence.

Third, on what comprises an ideal volunteer, C-Tayside described this as an eager volunteer who checks rafts frequently and communicates findings timely and accurately. Moreover, to her, ideal volunteers understand the "bigger picture" and "do things the way they are supposed to". C-Highlands said: "as far as I am concerned the best one is always the one that catches a lot of mink". For C-Cairngorms, the ideal volunteer was one that is keen and keeps in touch, while C-Aberdeenshire described the ideal volunteer as someone with a vested interest in the environment, who is "always vigilant".

Fourth, regarding interaction with volunteer, C-Tayside mentioned: "If you want people to do something you have got to (...) give it to them on a plate". This contrasted starkly with CAberdeenshire and C-Highlands who assumed that "if you do not hear anything there is nothing out there" (C-Highlands). C-Cairngorms explained that she generally speaks to "every single person in the same way", and that she tried to encourage volunteers "to contact me when they need to, rather than me having to contact [them]".

Fifth, volunteer feedback about the platform was the final dimension. C-Tayside and CCairngorms received mixed messages, with some volunteers submitting more records now than they did before, but with other volunteers who "do not want to have to sit in front of the computer" (C-Tayside). C-Highlands said he only received feedback from two volunteers about the platform, and concluded "I am not sure if [volunteers] actually use [it]". Likewise, C-Aberdeenshire noted: "The problems I have found (...) is that they are not overly keen in adopting new technology". 
Two key dimensions of 'innovation orientation' were identified, and for each diverging views were demonstrated among the coordinators (Table 1). The first dimension was that of own interaction with platform. The data revealed that all coordinators showed proficiency from the onset except for C-Aberdeenshire, who struggled to operate the platform on his own during the experiment and needed help from another coordinator. C-Highlands and CCairngorms seemed to have used the data collected by the platform at face value. Yet, CTayside used the platform to provide feedback to volunteers and to control the quality of incoming data: "when I get a message from the [platform] saying that somebody has entered data, I double-check it". Regarding the second dimension, expectations and opinion of platform, three coordinators believed the platform led to reduced administration workload, or that it would do so in the near future. C-Tayside, however, stressed that she still had to double-check all data that came in. But she also compared it to the situation before: "we needed to do something because it was no good the way it was"; "we had excel spreadsheets and they were just on our computers (...) that is never a good plan". She also expected the platform to become central to SMI's work in the future. C-Highlands said he had little dealings with it, but also stressed the importance of the platform for the future: "[no more] Excel sheets (...) a brilliant way to go". C-Cairngorms felt that improvements around the interface were still needed, but that it had helped in structuring SMI's operations. C-Aberdeenshire stressed the value of the "uniform approach" to data collection across SMI as a result of the platform.

\section{Discussion}


By experimentally launching a new data submission system we were able to demonstrate the gains this digital innovation pursued: more submissions, offered in smaller batch sizes at greater frequency. Yet, our approach was bound by some limitations related to this type of participatory research, such as an experimental runtime of 9.5 months and whether this was long enough to capture 'wear-off' from curiosity about a new digital platform. In addition, the generation of four experimental groups reveals that the implementation of a digital platform acts as a selector, attracting some and repelling others, and therefore likely changing volunteer demographics (Pagès et al., 2018). This raises the question whether volunteers who use such an innovation as intended are also those who serve the organisation best otherwise (e.g. the most active and persistent). Indeed, platform development revolving around data collection, as arguably is common amongst volunteerbased conservation organisations (Arts et al., 2015; Will et al., 2015), can sit at odds with drivers of volunteer motivation and retention. Our qualitative findings provide evidence for previous suggestions in this direction (Andow et al., 2016; Asah and Blahna, 2013; Bell et al., 2008; Bruyere and Rappe, 2007).

While the innovation was introduced organisation-wide, and highly valued by the director, each coordinator moderated the platform use by volunteers. Spanning much of Scotland, the coordinators operated in starkly differing physical environments, with different mink densities and 'types' of volunteers. Hence, it is possible that the nature of the regions indirectly demanded different engagement of coordinators towards the platform. But viewing the coordinators' operations in the context of their organisational and innovation orientations made understandable the differential use of platform regardless of differences in environmental context. While we did not have enough quantitative data to identify 
factors affecting coordinator engagement, our qualitative data points at the engagement of employees with new technology what is at stake here, whist finding no evidence for region specificity as additional key factor. With regard to the struggles of one coordinator with the technology, there is firstly the reality of a top down innovation decision by an organisation for its staff: not all employees might be able or willing to promote or use the innovation.

This seems a regularly overlooked element of innovation introduction in natural resource management (Arts et al., 2015; Jordan et al., 2012). Secondly, conservation organisations likely look for more computer-savvy staff if digital technology is to play a larger role in their futures. While both aspects are important, we have also found that - in light of the financial challenges that many conservation organisations or projects face (Arts et al., 2013; Sauermann and Franzoni, 2015; Will et al., 2015) - a digital platform may provide a backbone for continuity and stability; a central system to underpin effective data governance.

Whilst our studied initiative has characteristics which may differ from other organisations operating in natural resource management, such as being geographically highly dispersed and possibly demanding region-specific engagement of coordinators with their volunteers, we observe that the introduction of digital data submission platforms is a common innovation. Many conservation organisations face similar challenges in terms of lack of technical expertise, varying degrees of volunteer motivation, inefficient path-dependencies, and funding limitations (Bell et al., 2008; Newman et al., 2012, Pagès et al., 2019). These aspects are likely to drive leadership of conservation organisation (Dietz et al., 2004; Bruyere, 2015), with managers pushing more and more for digital innovation in order "to be more effective in achieving positive results" (Black et al., 2011: 329). 
Such top-down technological innovation is usually meant to be rolled out uniformly by conservation organisations. The role of the 'human layer' in between volunteers on the ground and conservation organisation policies is often taken for granted; yet, it is central to effective implementation of innovation (Newman et al., 2012). Our analysis has brought to light striking differences in how volunteers and coordinators engage with a newly introduced digital platform, collectively turning centralised innovation into new local realities. Our findings show that uniform implementation of digital innovation may not be achieved because of different organisational and innovation orientations of coordinators, and that differential appreciation among volunteers can directly affect data submission behaviour, and thus impact on a conservation organisation's goals and interests.

\section{Conclusion}

Following the co-development and introduction of a digital data-entry platform to aid conservation management, we set out to address two research aims: 1) to assess whether volunteer data submission changes with the use of a digital platform; and 2) to determine to what extent coordinators influence the usage of a digital platform by their volunteers. The merits of introducing a digital platform to aid conservation management resided primarily in changes in volunteer data submission: the number and frequency of submissions increased and batch sizes reduced. Moreover, the platform functioned as a backbone for continuity and stability, an aspect of digital innovation which may be particularly valuable for geographically dispersed initiatives.

Still, several pitfalls were identified too. Likely as a result of different organisational and innovation orientations, coordinators seemed to have influenced the adoption of a technology by volunteers, which was planned to be rolled out evenly across the initiative. 
This uniform implementation and affected the organisation's goals and interests. In addition, the introduction of the technology acted as a selector, attracting some volunteers but deterring others. This could change the 'type' of volunteers in the longer term, which may or may not suit the organisations' direction of travel. In particular, it remains to be seen whether digitalisation serves both the volunteer and the conservation initiative alike. Volunteer-based conservation initiatives are often grounded in physical work, which requires and attracts 'hands-on' volunteers (Pages et al 2019). Computer tasks may sit at odds with this, and thus a key motivation of volunteers to become involved.

Our conclusions lead to a message of caution in relation to the introduction of digital technologies; its merits, increased efficiency and efficacy of data collection and information handling, are not without pitfalls, which are notably human factors: volunteer attraction, retention and coordination. Conservation organisations should therefore not just blindly develop or implement digital tools, but also reflect on mediating factors and mechanism that ensure uptake and continued use of those tools.

\section{Acknowledgements}

We warmly thank the staff and volunteers of the Scottish Mink Initiative and RAFTS for their participation in this study, and two referees for their constructive comments on an earlier version of this paper. This research was supported by the award made by the RCUK Digital Economy programme to the dot.rural Digital Economy Hub, award reference:

EP/G066051/1. It has been ethically evaluated against the University of Aberdeen's Framework for Research Ethics and Governance. 


\section{References}

Andow, D.A., Borgida, E., Hurley, T.M., Williams, A.L., 2016. Recruitment and retention of volunteers in a citizen science network to detect invasive species on private lands. Environ. Manage. 58, 606-618.

Arts, K., Ioris, A.A.R., Macleod, C.J.A., Han, X., Sripada, S.G., Braga, J.R.Z., Van der Wal, R., 2016. Environmental communication in the Information Age: Institutional barriers and opportunities in the provision of river data to the general public. Environ. Sci. Policy 55, 47-53.

Arts, K., Van der Wal, R., Adams, W.M., 2015. Digital technology and the conservation of nature. Ambio 44, 661-673.

Arts, K., Webster, G., Sharma, N., Melero, Y., Mellish, C., Lambin, X., Van der Wal, R., 2013. Capturing mink and data: Interacting with a small and dispersed environmental, in: Framework for Responsible Research and Innovation in ICT FRRIICT - Case Study. pp. 15.

Asah, S.T., Blahna, D.J., 2013. Practical implications of understanding the influence of motivations on commitment to voluntary urban conservation stewardship. Conserv. Biol. 27, 866-875.

Asah, S.T., Blahna, D.J., 2012. Motivational functionalism and urban conservation stewardship: implications for volunteer involvement. Conserv. Lett. 5, 470-477.

Bakker, K., Ritts, M. 2018. Smart Earth: A meta-review and implications for environmental governance. Global Environ Chang. 52, 201-211.

Bates, D., Maechler, M., Bolker, B., Walker, S. 2015. Fitting linear mixed-effects models using Ime4. J Stat Softw 67, 1-48.

Black, S.A., Groombridge, J.J., Jones, C.G. 2011. Leadership and conservation effectiveness: 
Finding a better way to lead. Conserv. Lett. 4, 329-339.

Bekkers, V., Van Duivenboden, H., Thaens, M., 2006. Public innovation and information and communication technology: Relevant backgrounds and concepts, in: Information and Communication, Technology and Public Innovation: Assessing the ICT-Driven Modernization of Public Administration. IOS Press, Amsterdam, pp. 3-21.

Bell, S., Marzano, M., Cent, J., Kobierska, H., Podjed, D., Vandzinskaite, D., Reinert, H., Armaitiene, A., Grodzińska-Jurczak, M., Muršič, R., 2008. What counts? Volunteers and their organisations in the recording and monitoring of biodiversity. Biodivers. Conserv. $17,3443-3454$.

Bruyere, B.L., 2015. Giving direction and clarity to conservation leadership. Conserv. Lett. 8, $378-382$.

Bruyere, B., Rappe, S., 2007. Identifying the motivations of environmental volunteers. J. Environ. Plan. Manag. 50, 503-516.

Bryce, R., Oliver, M.K., Davies, L., Gray, H., Urquhart, J., Lambin, X., 2011. Turning back the tide of American mink invasion at an unprecedented scale through community participation and adaptive management. Biol. Conserv. 144, 575-583.

Chapron, G., 2015. Wildlife in the cloud: A new approach for engaging stakeholders in wildlife management. Ambio 44, 550-556.

Dickinson, J.L., Zuckerberg, B., Bonter, D.N., 2010. Citizen science as an ecological research tool: challenges and benefits. Annu. Rev. Ecol. Evol. Syst. 41, 149-172.

Dietz, J.M., Aviram, R., Bickford, S., Douthwaite, K., Goodstine, A., Izursa, J.L., Kavanaugh, S., MacCarthy, K., O'Herron, M., Parker, K. 2004. Defining leadership in conservation: A view from the top. Conserv. Biol. 18, 274-278.

Druschke, C.G., Seltzer, C.E., 2012. Failures of engagement: Lessons learned from a citizen 
science pilot study. Appl. Environ. Educ. Commun. 11, 178-188.

Fereday, J., Muir-Cochrane, E., 2006. Demonstrating rigor using thematic analysis: A hybrid approach of inductive and deductive coding and theme development. Int. J. Qual. methods 5, 80-92.

Galán-Díaz, C., Edwards, P., Nelson, J.D., Van der Wal, R., 2015. Digital innovation through partnership between nature conservation organisations and academia: A qualitative impact assessment. Ambio 44, 538-549.

Gallo, T., Waitt, D., 2011. Creating a successful citizen science model to detect and report invasive species. Bioscience 61, 459-465.

Hajer, M.A., van den Brink, M., Metze, T., 2006. Doing discourse analysis: coalitions, practices, meaning. Netherlands Geogr. Stud. (ISSN 0169-4839).

Jordan, R.C., Ballard, H.L., Phillips, T.B., 2012. Key issues and new approaches for evaluating citizen-science learning outcomes. Front. Ecol. Environ. 10, 307-309.

Jørgensen, M.W., Phillips, L.J., 2002. Discourse analysis as theory and method. Sage.

Kelling, S., Fink, D., La Sorte, F.A., Johnston, A., Bruns, N.E., Hochachka, W.M., 2015. Taking a 'Big Data'approach to data quality in a citizen science project. Ambio 44, 601-611.

Kobori, H., Dickinson, J.L., Washitani, I., Sakurai, R., Amano, T., Komatsu, N., Kitamura, W., Takagawa, S., Koyama, K., Ogawara, T., 2016. Citizen science: A new approach to advance ecology, education, and conservation. Ecol. Res. 31, 1-19.

Kremen, C., Ullman, K.S., Thorp, R.W., 2011. Evaluating the quality of citizen-scientist data on pollinator communities. Conserv. Biol. 25, 607-617.

Mace, G.M., 2014. Whose conservation? Science. 345, 1558-1560.

McCroskey, L.L., McCroskey, J.C., Richmond, V.P., 2005. Applying organizational orientations. theory to employees of profit and non-profit organizations. Commun. Q. 
53, 21-40.

Melero, Y., Robinson, E., Lambin, X., 2015. Density-and age-dependent reproduction partially compensates culling efforts of invasive non-native American mink. Biol. Invasions 17, 2645-2657.

Miller-Rushing, A., Primack, R., Bonney, R., 2012. The history of public participation in ecological research. Front. Ecol. Environ. 10, 285-290.

Newman, G., Wiggins, A., Crall, A., Graham, E., Newman, S., Crowston, K., 2012. The future of citizen science: emerging technologies and shifting paradigms. Front. Ecol. Environ. $10,298-304$

Pagès, M., Fischer, A., Van der Wal, R., 2018. The dynamics of volunteer motivations for engaging in the management of invasive plants: Insights from a mixed-methods study on Scottish seabird islands. J. Environ. Plan. Manag. 61, 904-923.

Pagès, M., Van der Wal, R., Lambin, X., Fischer, A. 2019. Empowered communities or "cheap labour"? Engaging volunteers in the rationalised management of invasive alien species in Great Britain. J. Environ. Manage. 229, 102-111.

Pruden, H.O., 1973. The upward mobile, indifferent, and ambivalent typology of managers. Acad. Manag. J. 16, 454-464.

Sauermann, H., Franzoni, C., 2015. Crowd science user contribution patterns and their implications. Proc. Natl. Acad. Sci. 112, 679-684.

Siguaw, J.A., Simpson, P.M., Enz, C.A., 2006. Conceptualizing innovation orientation: A framework for study and integration of innovation research. J. Prod. Innov. Manag. 23, $556-574$.

Stein, L.D., 2008. Towards a cyberinfrastructure for the biological sciences: progress, visions and challenges. Nat. Rev. Genet. 9, 678. 
Sullivan, B.L., Aycrigg, J.L., Barry, J.H., Bonney, R.E., Bruns, N., Cooper, C.B., Damoulas, T., Dhondt, A.A., Dietterich, T., Farnsworth, A., 2014. The eBird enterprise: An integrated approach to development and application of citizen science. Biol. Conserv. 169, 31-40.

Thomas, D.R., 2006. A general inductive approach for analyzing qualitative evaluation data. Am. J. Eval. 27, 237-246.

Tibbles, D., Richmond, V.P., McCroskey, J.C., Weber, K., 2008. Organizational orientations in an instructional setting. Commun. Educ. 57, 389-407.

Van der Wal, R., Sharma, N., Mellish, C., Robinson, A., Siddharthan, A., 2016. The role of automated feedback in training and retaining biological recorders for citizen science. Conserv. Biol. 30, 550-561.

Wald, D.M., Longo, J., Dobell, A.R., 2016. Design principles for engaging and retaining virtual citizen scientists. Conserv. Biol. 30, 562-570.

Wiersma, Y., 2010. Birding 2.0: Citizen science and effective monitoring in the Web 2.0. Avian Conserv. Ecol. 5, 1-9.

Will, D.J., Campbell, K.J., Holmes, N.D., 2015. Using digital data collection tools to improve overall cost-efficiency and provide timely analysis for decision making during invasive species eradication campaigns. Wildl. Res. 41, 499-509. 